\title{
Bmi1 - A Path to Targeting Cancer Stem Cells
}

\author{
David Bakhshinyan, ${ }^{1,2}$ Ashley A Adile, ${ }^{1,2}$ Chitra Venugopal ${ }^{1,3}$ and Sheila K Singh ${ }^{1,2,3}$
}

1. McMaster Stem Cell and Cancer Research Institute, McMaster University, Hamilton, ON, Canada; 2. Department of Biochemistry and Biomedical Sciences, Faculty of Health Sciences, McMaster University, Hamilton, ON, Canada; 3. Department of Surgery, Faculty of Health Sciences, McMaster University, Hamilton, ON, Canada he Polycomb group (PCG) genes encode for proteins comprising two multiprotein complexes, Polycomb repressive complex 1 (PRC1) and Polycomb repressive complex 2 (PRC2). Although the initial discovery of PCG genes was made in Drosophila, as transcriptional repressors of homeotic (HOX) genes. Polycomb repressive complexes have been since implicated in regulating a wide range of cellular processes, including differentiation and self-renewal in normal and cancer stem cells. Bmi1, a subunit of PRC1, has been long implicated in driving self-renewal, the key property of stem cells. Subsequent studies showing upregulation of Bmi1 in several cancers correlated with increased aggressiveness, radioresistance and metastatic potential, provided rationale for development of targeted therapies against Bmi1. Although Bmi1 activity can be reduced through transcriptional, post-transcriptional and post-translational regulation, to date, the most promising approach has been through small molecule inhibitors targeting Bmi1 activity. The post-translational targeting of Bmi1 in colorectal carcinoma, lung adenocarcinoma, multiple myeloma and medulloblastoma have led to significant reduction of self-renewal capacity of cancer stem cells, leading to slower tumour progression and reduced extent of metastatic spread. Further value of Bmi1 targeting in cancer can be established through trials evaluating the combinatorial effect of Bmi1 inhibition with current 'gold standard' therapies.

\section{Keywords}

Polycomb group (PCG) genes, Bmi1, Mel-18, cancer stem cells (CSCS), self-renewal

Disclosure: David Bakhshinyan, Ashley A Adile, Chitra Venugopal and Sheila K Singh have nothing to disclose in relation to this article. open Access: This article is published under the Creative Commons Attribution Noncommercial License, which permits any non-commercial use, distribution, adaptation and reproduction provided the original author(s) and source are given appropriate credit.

Compliance with Ethics: This study involves a review of the literature and did not involve any studies with human or animal subjects performed by any of the authors.

Received: 5 April 2017

Accepted: 12 July 2017

Citation: European Oncology \& Haematology, 2017;13(2):147-51

Corresponding Author: Sheila K Singh, Department of Surgery, McMaster Children's Hospital, Scientist, McMaster Stem Cell \& Cancer Research Institute, MDCL 5027, 1280 Main Street West, Hamilton, ON, L8S 4K1, Canada. E: ssingh@mcmaster.ca

Support: No funding was received for the publication of this article.
Since the discovery of the Polycomb group (PCG) gene family in Drosophila as repressors of homeotic (HOX) genes, PCG proteins have been implicated in a range of processes from chromosome $X$ inactivation to stem cell plasticity and differentiation. PCG proteins execute their function through transcriptional repression of the promoter region of a target gene. Although PCG proteins function as two major multiprotein complexes - Polycomb repressive complex 1 (PRC1) and Polycomb repressive complex 2 (PRC2) - the existence of several context specific subcomplexes has been postulated. ${ }^{1}$ PRC2 initiates gene silencing through the activity of histone deacetylase (HDAC), and histone methyltransferases that can methylate lysine 9 and 27 residues on histone $\mathrm{H} 3$ and lysine 26 on histone $\mathrm{H} 1$. $^{2-6}$ The stable gene repression is then maintained by PRC1 through recognition of tri-methylated H3K27 (H3K27me3). ${ }^{3}$ The canonical repression pathway is initiated through trimethylation of H3K27 on the promoter of target gene by PRC2 subunit EZH1 or its paralog EZH2. ${ }^{2-4}$ The H3K27me3 mark is readily recognised by PRC1 through chromatin binding ability of its subunit CBX. The repression is further maintained through ubiquitination of lysine 119 residue on histone H2A (H2AK119ub) by RING1, a subunit of PRC1, or chromatin condensation. ${ }^{-9}$ Promoters of the polycomb target genes have been generally characterised as CpG-rich DNA sequences that are lacking other epigenetic markers. ${ }^{10-14}$ However, several other models of context dependent PRC2 recruitment mechanisms, including Polycomb response elements (PRES) ${ }^{15-18}$ and nCRNAs ${ }^{19-22}$ have been investigated.

\section{Polycomb group genes and self-renewal}

Over the years, in addition to HOX genes, numerous targets of PCG repression have been identified, with one of the examples being CDKN2A locus (Figure 1). Encoding for p16 ${ }^{\text {INkAA }}$ and p14 ${ }^{\mathrm{ARF}}$ tumour-suppressor proteins, gene products of CDKN2A locus act as important mediators of the cell cycle..$^{23}$ The $16^{\text {INKaA }}$ prevents phosphorylation of retinoblastoma protein (RB) through inhibition of cyclin D-dependent CDK4 and CDK6, which allows hypophosphorylated $\mathrm{RB}$ to sequester E2F transcription factor and prevent activation of genes required for DNA replication. ${ }^{24}$ On the other hand, p14ARF interacts with MDM2 E3 ubiquitin ligase, preventing p53 polyubiquitination and subsequent p53 activation. ${ }^{25-28}$ The repression of CDKN2A by PCG proteins in stem cells, ${ }^{29,30}$ or its frequent deletion in cancer cells, ${ }^{31,32}$ facilitates increased self-renewal and proliferation, and has been implicated in neoplastic transformations. A meta-analysis of 11 studies quantifying CDKN2A methylation in 3,440 colorectal cancer patients, has identified hypermethylation in $23 \%$ of tumours. Furthermore, CDKN2A promoter hypermethylation was shown to correlate with poor patient overall survival. ${ }^{33}$ In juvenile myelomonocytic leukaemia (JMML), hypermethylation of CDKN2A was observed in 35\% of the patients and correlated with poor outcome, ${ }^{34}$ similarly to the patients diagnosed with non-small cell lung cancer 
Figure 1: Role of Bmi1 in driving self-renewal of cancer stem cells

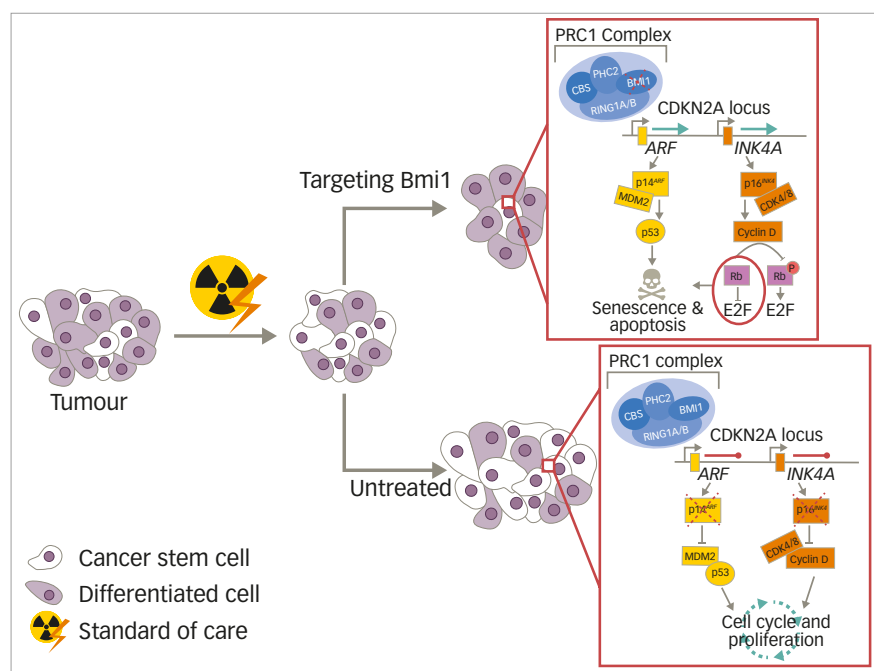

Cancer stem cells (CSCS) are endowed with the intrinsic ability to escape the best chemoradiotherapy regimens. Without targeted therapies against CSCS, slowly dividing cells left behind post-therapy will proliferate and drive tumour recurrence and metastatic spread. Within CSCS, Bmi1 directed self-renewal and proliferation is accomplished through transcriptional repression of the CDKN2A locus encoding for p16 $16^{\text {INAA }}$ and $p 14^{A R F}$. However, in the absence of Bmi1, p16-mediated inhibition of RB phosphorylation and p14-mediated prevention of p53 polyubiquitination, contribute to reduced activation of genes required for DNA replication and cell cycle progression. Through targeted therapies against Bmi1, it is possible to limit proliferation and self-renewal of the rare population of cells responsible for treatment failure and tumour recurrence. PRC1 = Polycomb repressive complex 1.

(NSCLC), hypermethylation of p16 promoter was also associated with worse outcome. ${ }^{35}$ The notion of slowing down the replication of cancer cells, a major hallmark of tumour biology, has been of great interest, and the efforts have escalated tremendously with the conceptualisation and discovery of cancer stem cells (CSCS). The first compelling evidence of cancer cells possessing stem-like properties came from the work of Bonnet and Dick in mouse models of acute myeloid leukaemia (AML). ${ }^{36}$ Since then, CSCs have been identified and characterised in breast, ${ }^{37}$ brain, ${ }^{38}$ colon $^{39}$ and lung ${ }^{40,41}$ cancers, among others. Due to their ability to evade chemoradiotherapy along with tumour-initiating and metastatic properties, CSCs have been implicated in driving treatment failure, tumour recurrence and poor clinical outcome. ${ }^{42}$ Although CSC populations identified in various cancer types have intrinsically different gene expression patterns, they all share the unique ability to self-renew, unlike the more differentiated cancer cells. This difference confers one of the major limitations of current therapy modalities, as they are effective against bulk tumour, consisting of highly proliferative cells, while sparing the intrinsically resistant, slow-dividing CSCs. The increasing evidence connecting self-renewal and therapeutic resistance of CSCS presents a strong rationale for developing novel therapeutic modalities as a treatment option for many aggressive malignancies. In this review, we discuss the involvement of PRC1 subunits, Bmi1 and Mel-18, in regulation of self-renewal in cancer and their potential for therapeutic targeting.

\section{Clinical implications of Bmi1 in cancer}

Bmi1, a 37kDa subunit of PRC1, was first identified as a key component in the activation region of Moloney murine leukaemia virus. ${ }^{43}$ The target gene suppression by PRC1 is primarily achieved through H2A119ub by RING1B E3 ligase, the catalytic activity of which is dramatically reduced in the absence of Bmi1. However, to date no specific enzymatic activity of Bmi1 has been reported, ${ }^{44}$ making it a challenge to target for therapeutic intervention. In early 2000s, Bmi1 was implicated in self-renewal of haematopoietic and neural stem cell populations, and driving the proliferation of early cerebellar progenitors. ${ }^{45-47}$ Further experimental evidence of importance of PCG gene in stem cells came from the study of Bmi1-deficient mice that suffered from continuous loss of haematopoietic cells and cerebellar neurons. ${ }^{48}$ PRC1 complex was further implicated in maintaining proper function of haematopoietic stem cells (HSCS) through interaction between Mph1/Rae28 with Bmi1. ${ }^{49}$ The oncogenic potential of Bmi1 became evident through investigation of lymphomagenesis in mouse models. Haupt et al. have demonstrated that in collaboration with c-Myc, Bmi1 contributed to lymphomagenesis in T and B cell lineages..$^{50}$ The PRC1-mediated transcriptional repression of CDKN2A locus during lymphomagenesis leads to maintenance of proliferative capacity and undifferentiated state, ${ }^{51,52}$ and has since been implicated in progression and poor prognosis in a number of haematologic malignancies. ${ }^{45,53}$ Similarly to normal stem cells, Bmi1 was implicated in maintenance of self-renewal in leukaemic stem and progenitor cells. ${ }^{54}$ Intriguingly, there is some evidence that Bmi1 can exert its oncogenic properties even in CDKN2A-deficient models, 55 suggesting the existence of other gene targets repressed during tumourigenesis. In addition to haematologic malignancies, ${ }^{53,56}$ elevated levels of Bmi1 have been shown in colorectal carcinoma, NSCLC, ${ }^{57}$ breast carcinoma, 5.59 glioblastoma (GBM), ${ }^{60}$ medulloblastoma ${ }^{61}$ and prostate cancer. ${ }^{62}$ Clinically, increased Bmi1 expression levels have been shown to correlate with poor patient prognosis in several aggressive cancer types, including colorectal carcinoma, ${ }^{63} \mathrm{GBM},{ }^{64}$ and medulloblastoma. ${ }^{65}$ The maintenance of self-renewal potential by Bmi1 contributes to the aggressive cancer phenotype by allowing CSCS to evade chemoradiotherapy regimens and drive tumour recurrence. Further contributions of Bmi1 to cancer cell survival through therapy has come from its role in promoting DNA damage repair. Both Bmi1 and Ring1B are recruited to the DNA doublestrand breaks (DSB) to facilitate ubiquitination of $\gamma \mathrm{H} 2 \mathrm{AX}$. ${ }^{66}$ The continuous localisation of Bmi1 to DSB is highly dependent on functionally intact ataxia-telangiectasia mutated (ATM), in addition to ATM- and Rad-3related (ATR) kinases. ${ }^{67,68}$ Moreover, Bmi1-driven enhancement of DNA DSB repair allows CSCS to negate the detrimental effects of radiation and persist post therapy. For example, in GBM, a highly malignant adult brain tumour, CD133 expressing brain tumour initiating cells (BTICS) ${ }^{38}$ were shown to have the capacity of escaping radiation through activation of DNA DSB repair mechanisms. ${ }^{69}$ However, the loss of Bmi1-assisted DNA DSB repair increases the sensitivity of CSCs to ionizing radiation, and promotes accumulation of cells in $\mathrm{G}_{2} / \mathrm{M}$ phase of the cell cycle. Aside from driving self-renewal and resistance to radiotherapy, Bmi1 has been implicated in promoting epithelial-mesenchymal transition (EMT), a signalling programme frequently associated with cancer invasion and metastatic potential, ${ }^{70}$ through cooperation with Twist 1 in head and neck carcinomas. ${ }^{11}$ By modulating SNAIL activity, Bmi1 is able to promote EMT through repression of PTEN and subsequent activation of AKT pathway. ${ }^{72}$ The apparent role of Bmi1 in maintaining a stem cell-like state and an invasive phenotype, along with its clinical significance in multiple tumour types, has prompted investigation into avenues of reducing Bmi1 levels as a potential therapeutic modality.

\section{Therapeutic targeting of Bmi1}

The extensive research on Bmi1 function in numerous malignancies has created a large amount of empirical data, correlating reduced Bmi1 expression levels with less proliferative, more therapy-sensitive and less tumourigenic phenotype of cancer cells. The development of small molecule inhibitors against Bmi1 might create an opportunity for designing therapies that not only target the highly proliferative cancer cells, but also the slowly dividing, therapy-evading CSCs. Additionally, Bmi1 targeting within CSCs can allow for modulation of two key tumour suppressor pathways driven by Rb and p53. In its turn, the combinatorial 
approach might allow for de-escalation of existing chemoradiotherapy protocols and minimise the associated toxicity and side effects. Decreased Bmi1 activity can be achieved through transcriptional, posttranscriptional or post-translational regulation..$^{73}$ In breast cancer cells, broad spectrum HDAC inhibitors have been shown to inhibit expression of Bmi1 and the activity of PRC1 complex as measured through a decrease of H1AK119ub. ${ }^{74,75}$ However, HDAC inhibitor-mediated reduction of Bmi1 expression is unlikely to be useful as a targeted therapy against cancer cells, and thus is likely to be associated with toxicity and side effects. In a recent publication by Kaneta et al., researchers have isolated and identified a series of naturally occurring compounds targeting Bmi1 promoter activity. The most active compound, wallichoside, was shown to decrease Bmi1 protein levels in colon carcinoma cells and reduced selfrenewing capacity of human hepatocellular carcinoma cells. ${ }^{76}$ However, further in vivo studies in human-mouse xenograft models are warranted to generate better understanding of the compound's therapeutic value. Additionally, molecules targeting Bmi1 transcript have been shown to hold a promising therapeutic potential in reducing oncogenic potential of prostate $\mathrm{CSCS}^{77}$ and hepatocellular carcinoma. ${ }^{78}$ Another potential way to modulate protein function, localisation and half-life is through posttranslational modifications. ${ }^{73}$ Targeting Bmi1 post-translationally, using small molecule inhibitors can present a more clinically relevant therapy modality with its potential to be selective for CSCs. The first experimental evidence demonstrating the imminent value of targeting Bmi1 through post-translational modification, came from the study conducted by Voncken et al. ${ }^{79}$ in 1999, where researchers observed fluctuating phosphorylation levels of Bmi1 through its progression in the cell cycle. In $\mathrm{G}_{1} / \mathrm{S}$ phase, hypophosphorylated Bmi1 is present in the chromatin-bound state, whereas the phosphorylation of Bmi1 in the $G_{2} / M$ phase reduces its chromatin association. Mechanistic insight into kinases involved in post-translational modification of Bmi1 came from the yeast two-hybrid interaction assay, which identified MAPKAP kinase 3pK as a regulator of Bmi1 chromatin association, among other PCG proteins. ${ }^{80}$ In recent years, small molecule inhibitors developed by PTC Therapeutics ( South Plainfield, $\mathrm{NJ}, \mathrm{US}$ ), were designed to promote phosphorylation of Bmi1, and have been tested in colorectal carcinomas, ${ }^{81}$ lung adenocarcinomas, ${ }^{82}$ multiple myeloma (MM), ${ }^{83}$ prostate cancer ${ }^{77}$ and medulloblastoma (unpublished data). In all cases, small molecule inhibitor resulted in decreased Bmi1 protein levels and reduced activity of the PRC1 complex. More importantly, diminished Bmi1 levels reduced the self-renewal capacity of CSCS, which in turn correlated with lowered tumourigenic potential in vitro and in vivo. In keeping with the original observations, cells treated with a Bmi1 inhibitor became more apoptotic ${ }^{77,81-83}$ and underwent cell cycle arrest at $\mathrm{G}_{0}$ phase. ${ }^{81,82}$ Collectively, these studies have provided a strong rationale for including Bmi1-targeted therapy in the treatment strategies for patients presenting with malignancies displaying elevated Bmi1 expression. Currently, the lead compound developed by PTC Therapeutics, PTC-596, is being examined in a phase I clinical trial (ClinicalTrials. gov identifier NCT02404480) for recurrent solid malignancies in adults. Another example of post-translational regulation of $\mathrm{Bmi} 1$ is through betatransducin repeat containing protein ( $\beta \operatorname{TrCP}$ ) mediated ubiquitination and subsequent degradation of Bmi1. In their work, Sahasrabuddhe et al. were able to demonstrate that wild-type Bmi1 is readily recognised and bound to by $\beta$ TrCP, a subunit of SCF (SKP1-cullin F-box) E3-ubiquitin ligase, and is destined for ubiquitin-proteasome mediated degradation. ${ }^{84}$ Development of therapies increasing the extent of Bmi1 ubiquitination might present an avenue to continuously reduce Bmi1 protein levels within the cell, and thus ensure un-inhibited transcription of CDKN2A locus.

In addition to development of small molecules directly affecting Bmi1 transcription or protein levels, novel compounds modulating
Bmi1 through inhibition of proteins that contribute to normal regulation of Bmi1, have been tested. Polo-like kinase 1 (PLK1) is overexpressed in several cancer subtypes, correlates with poor patient outcomes and has been shown to play an important role in driving tumour cell growth. 85,86 In breast cancer, small molecule inhibition of PLK1 resulted in marked induction of cellular senescence. Further experimentation revealed that downregulation of PLK1 activity caused upregulation of miR-200c and miR-141, which in turn, post-transcriptionally inhibited expression of Bmi1. ${ }^{87}$

\section{Negating Bmi1 effects by upregulation of Mel-18}

Despite the highly similar amino acid sequences and functional redundancy between Bmi1 and its paralog Mel-18, ${ }^{88}$ the two proteins differ in their regulation of PRC1 complex. Both Bmi1-PRC1 complex and Mel-18-PRC1 target genes with high levels H3K27me3 and contribute to the canonical PCG-mediated gene repression. ${ }^{12}$ However, in vitro studies in MCF7 cells indicated that Mel-18-PRC1 complexes have reduced ubiquitination activity compared to Bmi1-PRC1 complexes. ${ }^{44,89}$ It has also been postulated that increased levels of Mel-18 allows it to outcompete Bmi1 for integration into PRC1 and thus reduce the extent of PRC1 mediated gene repression..$^{90}$ Interestingly, the expression pattern of Bmi1 and Mel-18 varies in adult tissues suggesting regulation of distinct cellular programmes. ${ }^{12,91}$ In contrast to Bmi1, expression levels of Mel-18 escalate during differentiation of $\mathrm{HSCS}^{4}, 4,54,91$ suggesting that while Bmi1 is essential in preserving HSCs, Mel-18 ensures proper differentiation. ${ }^{22,93}$ Further functional differences between Bmi1 and Mel-18 extend to their role in cancer cells. Unlike Bmi1, that is often upregulated in aggressive cancers, Mel-18 is often downregulated, ${ }^{94-100}$ suggesting a tumour suppressive role. Studies in human fibroblasts identified Mel-18 contribution to transcriptional regulation of Bmi1 through modulation of c-Myc levels. The Mel-18-driven downregulation of c-Myc during cellular senescence reduces its binding to the Bmi1 promoter, and thus stalls Bmi1 gene expression. ${ }^{6,101-103}$ Several other pathways modulated by Mel-18 include Wnt signalling, E-cadherin and angiogenesis. ${ }^{104-106}$ From a therapeutic perspective, Mel-18 presents an intriguing possibility to negate Bmi1 activity through Mel-18 agonists. The increased levels of Mel-18 will allow for formation of more Mel-18-PRC1 complexes that have opposing effects to Bmi1-PRC1 complexes and thus will reduce the extent to which Bmi1 is able to contribute to therapy evasion and selfrenewal ability of CSCS.

\section{Concluding remarks}

A combinatorial approach of targeting the bulk tumour population, along with the CSC fraction can potentially not only lead to de-escalation of current treatment protocols, but also address the root cause of tumour recurrence. However, since Bmi1 is ubiquitously expressed throughout the human body, the effects of Bmi1 targeting must be carefully and methodically evaluated. In the pre-clinical models investigating the efficacy of Bmi1 targeting with small molecule inhibitors for treatment of childhood medulloblastoma, our lab has shown a higher sensitivity of tumour cells to the Bmi1 inhibitor, relative to neural stem cells (unpublished data). These results highlight the importance of further elucidating different Bmi1 roles and its regulation in cancer cells, when compared to normal cells. The increasing evidence demonstrating Bmi1driven therapy evasion and tumour recurrence warrants routine profiling of Bmi1 levels in oncologic patients, in order to identify patients who have the potential to benefit from combining Bmi1 targeted therapies with today's gold standard chemoradiotherapies. Moreover, the relationship between Bmi1 and Mel-18 requires further investigation as indirect modulation of Bmi1 levels by Mel-18 can create new therapeutic avenues for minimising oncogenic effects of Bmi1. $\square$ 
1. Otte AP, Kwaks TH, Gene repression by Polycomb group protein complexes: a distinct complex for every occasion?, Curr Opin Genet Dev, 2003:13:448-54.

2. Cao $\mathrm{R}$, Wang $\mathrm{L}$, Wang $\mathrm{H}$, et al., Role of histone $\mathrm{H} 3$ lysine 27 methylation in Polycomb-group silencing, Science 2002;298:1039-43

3. Czermin B, Melfi R, McCabe D, et al., Drosophila enhancer of Zeste/ESC complexes have a histone $\mathrm{H} 3$ methyltransferase activity that marks chromosomal Polycomb sites, Cell, 2002;111:185-96.

4. Muller J, Hart CM, Francis NJ, et al., Histone methyltransferase activity of a Drosophila Polycomb group repressor complex Cell, 2002;111:197-208.

5. Kuzmichev A, Jenuwein $T$, Tempst P, Reinberg D, Different EZH2-containing complexes target methylation of histone $\mathrm{H} 1$ or nucleosomal histone $\mathrm{H3}$, Mol Cell, 2004;14:183-93.

6. van der Vlag J, Otte AP, Transcriptional repression mediated by the human polycomb-group protein EED involves histone deacetylation, Nat Genet, 1999;23:474-8.

7. Min G, Zhou G, Schapira M, et al., Structural basis of urothelial permeability barrier function as revealed by Cryo-EM studies of the $16 \mathrm{~nm}$ uroplakin particle, I Cell Sci, 2003;116:4087-94

8. Fischle W, Wang Y, Jacobs SA, et al., Molecular basis for the discrimination of repressive methyl-lysine marks in histon H3 by Polycomb and HP1 chromodomains, Genes Dev 2003; 17:1870-81.

9. Wang $\mathrm{H}$, Wang $\mathrm{L}$, Erdjument-Bromage $\mathrm{H}$, et al., Role of histone $\mathrm{H} 2 \mathrm{~A}$ ubiquitination in Polycomb silencing, Nature 2004;431:873-8.

10. Ku M, Koche RP, Rheinbay E, et al., Genomewide analysis of PRC1 and PRC2 occupancy identifies two classes of bivalent domains, PLOS Genet,2008;4:e1000242.

11. Lynch MD, Smith Al, De Gobbi M, et al., An interspecies analysis reveals a key role for unmethylated CPG dinucleotides in vertebrate Polycomb complex recruitment, EMBO 2012;31:317-29.

12. Gao $Z$, Zhang J, Bonasio $R$, et al., PCGF homologs, CBX proteins, and RYBP define functionally distinct PRC1 family complexes, Mol Cell, 2012;45:344-56

13. Jermann P, Hoerner L, Burger L, Schubeler D, Short sequences can efficiently recruit histone $\mathrm{H} 3$ lysine 27 trimethylation in the absence of enhancer activity and DNA methylation, Proc Natl Acad Sci U S A, 2014;111:E3415-21.

14. Mendenhall EM, Koche RP, Truong T, et al., GC-rich sequence elements recruit PRC2 in mammalian ES cells, PLOS Genet, 2010;6:e1001244.

15. Bengani $\mathrm{H}$, Mendiratta S, Maini J, et al., Identification and Validation of a Putative Polycomb Responsive Element in the Human Genome, PLOS One, 2013:8:e67217.

16. Woo $\mathrm{CJ}$, Kharchenko PV, Daheron L, et al., A region of the human HOXD cluster that confers polycomb-group responsiveness, Cell, 2010;140:99-110.

17. Sing A, Pannell D, Karaiskakis A, et al., A vertebrate Polycomb response element governs segmentation of the posterio hindbrain, Cell, 2009;138:885-97.

18. Cuddapah S, Roh TY, Cui K, et al., A novel human polycomb binding site acts as a functional polycomb response element in Drosophila, PLoS One, 2012;7:e36365.

19. Aguilo F, Zhou MM, Walsh MJ, Long noncoding RNA, polycomb, and the ghosts haunting INKAb-ARF-INK4a expression, Cancer Res, 2011;71:5365-9.

20. Brockdorff N, Noncoding RNA and Polycomb recruitment, RNA 2013:19:429-42

21. Karapetyan AR, Buiting C, Kuiper RA Coolen MW, Regulatory roles for long ncRNA and mRNA, Cancers (Basel). 2013:5:462-90.

22. Peschansky VJ, Wahlestedt C, Non-coding RNAs as direct and indirect modulators of epigenetic regulation, Epigenetics, 2014;9:3-12.

23. Sharpless NE, Sherr CJ, Forging a signature of in vivo senescence, Nat Rev Cancer, 2015;15:397-408.

24. Serrano M, Hannon GJ, Beach DA, new regulatory motif in cell-cycle control causing specific inhibition of cyclin D/CDK Nature, 1993:366:704-7.

25. Kamijo T, Zindy F, Roussel MF, et al., Tumor suppression at the mouse INK 4 a locus mediated by the alternative reading frame product p19ARE, Cell 1997:91:649-59.

26. Pomerantz J, Schreiber-Agus $\mathrm{N}$, Liégeois NJ, et al., The Ink4a tumor suppressor gene product, p19Arf, interacts with MDM2 and neutralizes MDM2's inhibition of p53, Cell, 1998:92:713-23.

27. Zhang Y, Xiong Y, Yarbrough WG, ARF promotes MDM2 degradation and stabilizes p53: ARF-INK4a locus deletion impairs both the Rb and p53 tumor suppression pathways, Cell

28. Kamijo T, Weber JD, Zambetti G, et al., Functional and physical interactions of the ARF tumor suppressor with p53 and Mdm2 Proc Natl Acad Sci U S A, 1998;95:8292-7.

29. Sharpless NE, DePinho RA, How stem cells age and why this makes us grow old, Nat Rev Mol Cell Biol, 2007;8:703-13.

30. Signer RA, Morrison SJ, Mechanisms that regulate stem cell aging and life span, Cell Stem Cell, 2013;12:152-65.

1. Chandler $H$, Peters $G$, Stressing the cell cycle in senescence and aging, Curr Opin Cell Biol, 2013;25:765-71.

32. Bignell GR, Greenman $C D$, Davies $H$, et al., Signatures of mutation and selection in the cancer genome, Nature, 2010;463:893-8.

33. Xing $X$, Cai W, Shi $H$, et al., The prognostic value of CDKN2A hypermethylation in colorectal cancer: a meta-analysis, $\mathrm{Br} \perp$ Cancer, 2013;108:2542-8.

34. Sakaguchi H, Muramatsu H, Okuno Y, et al., Aberrant DNA methylation is associated with a poor outcome in juvenil myelomonocytic leukemia, PLoS One, 2015;10:e0145394.

35. Bradly DP, Gattuso P, Pool M, et al., CDKN2A (p16) promoter hypermethylation influences the outcome in young lung cancer patients, Diagn Mol Pathol, 2012:21:207-13.

36. Bonnet $D$, Dick JE, Human acute myeloid leukemia is organized as a hierarchy that originates from a primitive hematopoietic cell, Nat Med, 1997:3:730-7.

37. Al-Hajj M, Wicha MS, Benito-Hernandez A, et al., Prospective identification of tumorigenic breast cancer cells, Proc Natl Acad SCi U S A, 2003;100:3983-8.

38. Singh SK, Hawkins C, Clarke ID, et al., Identification of human brain tumour initiating cells, Nature, 2004;432:396-401.

39. Barker N, van ES JH, Kuipers J, et al., Identification of stem cells in small intestine and colon by marker gene Lgr5, Nature, 2007:449:1003-7.

40. Ho MM, Ng AV, Lam S, Hung JY, Side population in human lung cancer cell lines and tumors is enriched with stem-like cance cells, Cancer Res, 2007:67:4827-33.

41. Salcido CD, Larochelle A, Taylor BJ, et al., Molecular characterisation of side population cells with cancer stem cell-like characteristics in small-cell lung cancer, Br J Cancer, 2010:102:1636-44.

42. Allen KE, Weiss GJ, Resistance may not be futile: microRNA biomarkers for chemoresistance and potential therapeutics, Mol Cancer Ther, 2010;9:3126-36.

43. Alkema MJ, Wiegant J, Raap AK, et al., Characterization and chromosomal localization of the human proto-oncogene BMIHum Mol Genet, 1993;2:1597-603.

44. Cao R, Tsukada $Y$, Zhang $Y$, Role of Bmi-1 and Ring1A in $\mathrm{H} 2 \mathrm{~A}$ ubiquitylation and $\mathrm{Hox}$ gene silencing, $\mathrm{Mol} \mathrm{Ce} /{ }^{\prime}$ 2005;20:845-54

45. Lessard J, Sauvageau G, Bmi-1 determines the proliferative capacity of normal and leukaemic stem cells, Nature, 2003;423:255-60

46. Park IK, Qian D, Kiel M, et al., Bmi-1 is required for maintenance of adult self-renewing haematopoietic stem cells, Nature 2003:423:302-5

47. Molofsky AV, Pardal R, Iwashita T, et al., Bmi-1 dependence distinguishes neural stem cell self-renewal from progenito proliferation, Nature, 2003:425:962-7.

48. van der Lugt NM, Domen J, Linders K, et al., Posterior transformation, neurological abnormalities, and severe hematopoietic defects in mice with a targeted deletion of the bmi-1 proto-oncogene, Genes Dev, 1994;8:757-69.

49. Ohta H, Sawada A, Kim JY, et al., Polycomb group gene rae28 required for sustaining activity of hematopoietic stem cells, J Exp Med, 2002;195:759-70

50. Haupt $Y$, Bath ML, Harris AW Adams JM, bmi-1 transgene induces lymphomas and collaborates with myc in tumorigenesis, Oncogene, 1993:8:3161-4.

51. Jacobs JJ, Scheijen B, Voncken JW, et al., Bmi-1 collaborates with C-Myc in tumorigenesis by inhibiting c-Myc-induced int C-Myc in tNK 1 .

52. Itahana $K$, Zou $Y$, Itahana $Y$, et al., Control of the replicative life span of human fibroblasts by $\mathrm{p} 16$ and the polycomb protein Bmi-1, Mol Cell Biol, 2003;23:389-401

53. Hosen N, Yamane T, Muijtjens M, et al., Bmi-1-green fluorescent protein-knock-in mice reveal the dynamic regulation of bmi-1 expression in normal and leukemic hematopoietic cells, Stem Cells, 2007;25:1635-44

54. Schuringa JJ, Vellenga E, Role of the polycomb group gene BMI in normal and leukemic hematopoietic stem and progenitor cells, Curr Opin Hematol, 2010:17:294-9.

55. Bruggeman SW, Hulsman D, Tanger E, et al., Bmi1 controls tumor development in an Ink4a/Arf-independent manner in mouse model for glioma, Cancer Cell, 2007:12:328-41.

56. Merkerova M, Bruchova H, Kracmarova A, et al., Bmi-1 overexpression plays a secondary role in chronic myeloid leukemia transformation, Leuk Lymphoma, 2007:48:793-801.

57. Vrzalikova K, Skarda J, Ehrmann J, et al., Prognostic value of Bmi-1 oncoprotein expression in NSCLC patients: a tissue microarray study, I Cancer Res Clin Oncol, 2008;134:1037-42

58. Honig A, Weidler $\mathrm{C}$, Häusler $\mathrm{S}$, et al., Overexpression of polycomb protein BMI-1 in human specimens of breast,
ovarian, endometrial and cervical cancer, Anticancer Res, 2010;30:1559-64.

59. Guo BH, Feng $Y$, Zhang R, et al., Bmi-1 promotes invasion and metastasis, and its elevated expression is correlate with an advanc

60. Abdouh M, Facchino S, Chatoo W, et al., BMI1 sustains human glioblastoma multiforme stem cell renewal,, Neurosci, 2009:29:8884-96.

61. Leung C, Lingbeek M, Shakhova O, et al., Bmi1 is essentia for cerebellar development and is overexpressed in human medulloblastomas, Nature, 2004;428:337-41.

62. Glinsky GV, Stem cell origin of death-from-cancer phenotypes of human prostate and breast cancers, Stem Cell Rev, 2007;3:79-93.

63. Li DW, Tang HM, Fan JW, et al., Expression level of Bmi-1 oncoprotein is associated with progression and prognosis in colon cancer, I Cancer Res Clin Oncol, 2010;136:997-1006.

64. Cenci T, Martini M, Montano N, et al., Prognostic relevance of C-Myc and BMl1 expression in patients with glioblastoma, Am I Clin Pathol, 2012:138:390-6.

65. Manoranjan B, Wang X, Hallett RM, et al., FoxG1 interacts with $B$ mi1 to regulate self-renewal and tumorigenicity of medulloblastoma stem cells, Stem Cells, 2013;31:1266-77.

66. Ismail IH, Andrin C, MCDonald D, Hendzel MJ, BMI1-mediated histone ubiquitylation promotes DNA double-strand break repair, I Cell Biol, 2010:191:45-60.

67. Marechal A, Zou L, DNA damage sensing by the ATM and ATR kinases, Cold Spring Harb Perspect Biol, 2013;5:pii: a012716.

68. Ginjala V, Nacerddine K, Kulkarni A, et al., BMI1 is recruited to DNA breaks and contributes to DNA damage-induced H2A ubiquitination and repair, Mol Cell Biol, 2011;31:1972-82.

69. Facchino S, Abdouh M, Chatoo W, Bernier G, BMl1 confers radioresistance to normal and cancerous neural stem cells through recruitment of the DNA damage response machinery, Neurosci, 2010:30:10096-111.

70. Singh A, Settleman J, EMT, cancer stem cells and drug resistance: an emerging axis of evil in the war on cancer,

71. Yang MH, Hsu DS, Wang HW, et al., Bmi1 is essential in Twist1induced epithelial-mesenchymal transition, Nat Cell Biol, 2010;12:982-92.

72. Song LB, Li J, Liao WT, et al., The polycomb group protein Bmi-1 represses the tumor suppressor PTEN and induces epithelialmesenchymal transition in human nasopharyngeal epithelia cells, I Clin Invest, 2009;119:3626-36.

73. Cao L, Bombard J, Cintron K, et al., BMI1 as a novel target for drug discovery in cancer, I Cell Biochem, 2011;112:2729-41.

74. Bommi PV, Dimri M, Sahasrabuddhe AA, et al., The polycomb group protein BMI1 is a transcriptional target of HDAC inhibitors, Cell Cycle, 2010:9:2663-73.

75. Jung JW, Lee S, Seo MS, et al., Histone deacetylase controls adult stem cell aging by balancing the expression of polycom genes and jumonji domain containing 3, Cell Mol Life SCi, 2010;67:1165-76

76. Kaneta Y, Arai MA, Ishikawa N, et al., Identification of BMI1 Promoter Inhibitors from Beaumontia murtonii and Eugenia operculata, I Nat Prod, 2017;80:1853-9.

77. Bansal N, Bartucci M, Yusuff S, et al., BMl-1 Targeting Interferes with Patient-Derived Tumor-Initiating Cell Surviva and Tumor Growth in Prostate Cancer, Clin Cancer Res, 2016;22:6176-91

78. Bartucci M, Hussein MS, Huselid E, et al., Synthesis and Characterization of Novel BMI1 Inhibitors Targeting Cellular Self-Renewal in Hepatocellular Carcinoma, Target Oncol, 2017:12:449-62.

79. Voncken JW, Schweizer D, Aagaard L et al, Chromatinassociation of the Polycomb group protein BMl1 is cell cycleregulated and correlates with its phosphorylation status, $J$ Cell SCi, 1999;112:4627-39.

80. Voncken JW, Niessen H, Neufeld B, et al., MAPKAP kinase 3pK phosphorylates and regulates chromatin association of the polycomb group protein Bmi1, J Biol Chem, 2005;280:5178-87.

81. Kreso A, van Galen P, Pedley NM, et al., Self-renewal as a therapeutic target in human colorectal cancer, Nat Med, 2014;20:29-36.

82. Yong KJ, Basseres DS, Welner RS, et al., Targeted BMI1 inhibition impairs tumor growth in lung adenocarcinomas with low CEBPalpha expression, Sci Trans/ Med, 2016:8:350ra104

83. Bolomsky A, Schlangen $\mathrm{K}$, Schreiner $\mathrm{W}$, et al., Targeting of BMI-1 with PFC-209 shows potent anti-nyeloma activity and impairs the tumour microenvironment, I Hematol Oncol, 2016;9:17

84. Sahasrabuddhe AA, Dimri M, Bommi PV, Dimri GP, betaTrCP regulates BMI1 protein turnover via ubiquitination and degradation, Cell Cycle, 2011;10:1322-30.

85. Strebhardt K, Multifaceted polo-like kinases: drug targets and antitargets for cancer therapy, Nat Rev Drug Discov 2010;9:643-60

86. Strebhardt K, Ullrich A, Targeting polo-like kinase 1 for cancer therapy Nat Rev Cancer, 2006;6:321-30.

87. Dimri M, Cho JH, Kang M, Dimri GP, PLK1 inhibition down-regulates polycomb group protein BMI1 via modulation of the miR-200C/141 cluster, J Biol Chem 2015;290:3033-44.

88. van Lohuizen M, Frasch $M$, Wientjens $E$, Berns $A$, Sequence similarity between the mammalian bmi-1 proto-oncogene and the Drosophila regulatory genes Psc and Su(z)2, Nature 1991;353:353-5

89. Qian T, Lee JY, Park JH, et al., Id1 enhances RING1b E3 ubiquitin ligase activity through the Mel-18/Bmi-1 polycomb group complex, Oncogene, 2010;29:5818-27.

90. Koppens M, van Lohuizen M, Context-dependent actions of Polycomb repressors in cancer, Oncogene, 2016;35:1341-52.

91. Lessard J, Baban S, Sauvageau G, Stage-specific expression of polycomb group genes in human bone marrow cells, Blood, 1998:91:1216-24.

92. Kajiume T, Ohno N, Sera Y, et al., Reciprocal expression of Bmi1 and Mel-18 is associated with functioning of primitive hematopoietic cells, Exp Hematol, 2009;37:857-66.

93. Oguro $\mathrm{H}$, Yuan J, Ichikawa $\mathrm{H}$, et al., Poised lineage specification in multipotential hematopoietic stem and progenitor cells by the polycomb protein Bmi1, Cell Stem Cell, 2010;6:279-86 
99. Zhang XW, Sheng YP, Li Q, et al., BMI1 and Mel-18 oppositely regulate carcinogenesis and progression of gastric cancer Mol Cancer, 2010:9:40

100. Lu YW, Li J, Guo WJ, Expression and clinicopathological significance of Mel-18 and Bmi-1 mRNA in gastric carcinoma, J Exp Clin Cancer Res, 2010;29:143.

01. Tetsu O, Ishihara H, Kanno R, et al., mel-18 negatively regulates cell cycle progression upon $\mathrm{B}$ cell antigen receptor stimulation through a cascade leading to c-myc/cdc25, Immunity, 1998;9:439-48.
102. Guo WJ, Datta S, Band V, Dimri GP, Mel-18, a polycomb group protein, regulates cell proliferation and senescence via transcriptional repression of Bmi-1 and c-Myc oncoproteins, Mol Biol Cell, 2007;18:536-46.

103. Kanno M, Hasegawa M, Ishida A, et al., mel-18, a Polycomb group-related mammalian gene, encodes a transcriptional negative regulator with tumor suppressive activity, EMBO 1995; 14:5672-8.

104. Lee JY, Park MK, Park JH, et al., Loss of the polycomb protein Mel-18 enhances the epithelial-mesenchymal transition by
ZEB1 and ZEB2 expression through the downregulation of miR205 in breast cancer, Oncogene, 2014;33:1325-35.

105. Guo BH, Zhang $X$, Zhang HZ, et al., Low expression of Mel-18 predicts poor prognosis in patients with breast cancer, $A n n$ Oncol, 2010;21:2361-9.

106. Park JH, Lee JY, Shin DH, et al., Loss of Mel-18 induces

tumor angiogenesis through enhancing the activity and expression of HIF-1alpha mediated by the PTEN/PI3K/Akt pathway, Oncogene, 2011;30:4578-89. 